\title{
Isolated adrenocorticotropic hormone deficiency not always permanent
}

\begin{abstract}
Isolated Adrenocorticotrophic hormone (ACTH) deficiency is rare but could be a lifethreatening condition characterized by hypocortisolism. Most causes are secondary to autoimmune process such as lymphocytic hypophysitis. It may also occur after traumatic brain injury, tumors, pituitary irradiation and ischemic brain insult. Genetic causes are not infrequent. We present two causes of Isolated Adrenocorticotrophic Hormone $(\mathrm{ACTH})$ deficiency who experienced different outcomes and highlight the importance of understanding the various possible aetio-pathophysiology.
\end{abstract}

Keywords: adrenocorticotrophic hormone deficiency, aetio-pathophysiology, isolated, permanent, transient
Volume 5 Issue 2 - 2017

\author{
Nasir AM Al Jurayyan \\ Department of Pediatrics, King Saud University, Saudi Arabia \\ Correspondence: Nasir AM Al Jurayyan, Professor and Senior \\ Consultant Pediatric Endocrinologist Division of Endocrinology, \\ Department of Pediatrics, College of Medicine \& King Khalid \\ University Hospital, P.O Box 2925, Riyadh I I 46I, Saudi Arabia, \\ Tel 00966-I I-4670807, Fax 00966-I I-467| 506, \\ Email njurayyan@gmail.com
}

Received: July 23, 2017 | Published: October 20, 2017
Abbreviations: ACTH, adrenocorticotrophic hormone; ITT, insulin tolerance test; HPA, hypothalamic pituitary adrenal; PGE, prostaglandin effects

\section{Introduction}

Adrenocorticotrophic Hormone (ACTH) deficiency is the most lifethreatening feature of hypopituitarism. Isolated Adrenocorticotrophic Hormone (ACTH) deficiency, although well defined, is very rare. ${ }^{1}$ Its clinical manifestations are similar to those of Addison's disease, i.e weakness, tiredness, nausea, vomiting, orthostatic hypotension, anorexia, weight loss, and most commonly hypoglycemia. However, rare presentism may occur. ${ }^{3,4}$ Most causes are secondary to autoimmune process such as lymphocytic hypophysitis. ${ }^{5,6}$ It may also occur after traumatic head injury and pituitary irradiation. ${ }^{7,8}$ Genetic is encountered in the neonatal and childhood. ${ }^{9,10}$ It might be associated with transient growth hormone $(\mathrm{GH})$ deficiency or thyroid disorders. ${ }^{11,12}$ Also, various toxins were associated with the deficiency. ${ }^{13}$ In this communication, we describe two patients with Isolated Adrenocorticotrophic Hormone (ACTH) deficiency that experienced two different outcomes (transient vs. permanent) with an attempt to highlight the importance of understanding such disorders and its aetio-pathophysiology.

\section{Case I}

Previously healthy 11-5years old boy was brought to the emergency room having been found unconscious in bed. He had been unwell for few days with decreased activity and muscle pain. He was unconscious and febrile with no other physical abnormalities except for signs of upper respiratory tract infection. He was hypoglycemic (plasma glucose $1.1 \mathrm{mmol} / 1$ ) and was successfully resuscitated with intravenous dextrose. All subsequent blood glucose concentrations were normal on intravenous glucose and then on normal diet. Investigations showed normal hematology, electrolyte and liver function. He recovered rapidly and was discharged in good health after 5 days. Five months later, he was readmitted with hypoglycemic coma following an upper respiratory tract infection. His plasma glucose was $0.9 \mathrm{mmol} / 1$, resuscitation was successful with intravenous dextrose and hydrocortisone, after blood being taken for cortisol, ACTH insulin and growth hormone. He was then transferred for further investigations. He was delivered by caesarian section for failure to progress. There was no evidence of increased intracranial pressure and no history of head trauma. His neuro physical developments were normal, and there was no family history of endocrine disorders. On physical examination, the boy appeared healthy; he was $151 \mathrm{~cm}$ tall and weighed $34 \mathrm{~kg}$ blood pressure was $100 / 60 \mathrm{~mm} \mathrm{Hg}$. No skin hyper pigmentation was observed and liver was not palpable. The pubic hair was at Tanner stage II. Laboratory investigations revealed normal blood count and bone, renal and liver profiles. Hormonal values at the time of presentation revealed: serum cortisol (Amerlite cortisol assay, Amersham, UK. with a measurement range of 0-1.700nmol/1, and a sensitivity of $3 \mathrm{nmol} / \mathrm{l}$ ) was low at $3 \mathrm{nmol} / 1$ (normal range: 150 600 ), with undetectable ACTH (commercial RIA kits, Bioscientia Laboratories, Germany) of less than 1pmol/1 (normal range:5-18). Serum insulin (RIA kits, CIS, Gif-sur-Yvette, France, with a sensitivity limit of $14 \mathrm{pmol} / \mathrm{l}$ and an interassay coefficient of variation of $8.2 \%$ at a serum concentration of $126 \mathrm{pmol} / 1$ ) was $26 \mathrm{pmol} / 1$ (normal range:35-150), at plasma glucose of $0.9 \mathrm{mmo} / 1$. Following prolonged fasting (14h) and while off hydrocortisone the patient developed an hypoglycemic attack (plasma glucose $1.6 \mathrm{mmol} / \mathrm{l}$ ) during which serum cortisol was less than $3 \mathrm{nmol} / 1$, ACTH less than $1 \mathrm{pmol} / 1$, insulin $50 \mathrm{pmol} / 1$ and $\mathrm{GH} 0.45 \mathrm{pmol} / 1$. A short Synacthen test (250ug i.v.) showed no cortisol response (Table 1). Insulin-induced hypoglycemia using $0.075 \mathrm{U} / \mathrm{kg}$ body weight revealed blunted response of cortisol and ACTH (Table 2), while TRH (200ug i.v.) and LHRH tests (100ug i.v.) showed normal responses for age (Table 3 ). GH response to clonidine and insulin-induced hypoglycemia was also normal. Organ-specific antibodies including anterior pituitary, adrenal cortex, parietal and islet cells were negative by indirect immuno fluorescence as well as thyroglobulin and thyroid microsomal antibodies (haemagglutination method). High-resolution CT scan and MRI failed to reveal any anatomical abnormality of the sella and suprasellar region. 
Table I Synacthen test

\begin{tabular}{lll}
\hline & Acth & Cortisol \\
Adrenal Function & $(1.6-13.9 \mathrm{Pmol} / \mathrm{L})$ & $(150-630 \mathrm{Nmol} / \mathrm{L})$ \\
(Base-Line Result) & Less than $1 \mathrm{Pmol} / \mathrm{L}$ & Less than $3 \mathrm{Nmol} / \mathrm{L}$ \\
& $30 \mathrm{Min}$ & $60 \mathrm{Min}$ \\
\multirow{2}{*}{ Post Stimulation Cortisol } & Less than 3 & Less than 3 \\
\hline
\end{tabular}

Table 2 Evels of blood glucose, cortisol and ACTH after intra-venous insulin

\begin{tabular}{llll}
\hline \multirow{2}{*}{ Time in min } & $\begin{array}{l}\text { Glucose } \\
\text { Mmol/l }\end{array}$ & Cortisol & ACTH \\
\cline { 3 - 4 } & 4.6 & $<3$ & $\mathbf{~} \mathbf{\text { mmol} / \mathbf { 1 }}$ \\
\hline 0 & 2.2 & $<3$ & $<1$ \\
20 & 2.1 & - & - \\
40 & 1.9 & $<3$ & $<1$ \\
603 & 2.1 & $<3$ & - \\
80 & 2.7 & - & - \\
100 & 3.7 & $<3$ & - \\
120 & & & $<1$ \\
\hline
\end{tabular}

Glucose given intravenously

Table 3 Plasma levels of LH, FSH and TSH after LHRH and TRH stimulations

\begin{tabular}{llll}
\hline Time in min & $\begin{array}{l}\text { LH } \\
\text { IU/I }\end{array}$ & $\begin{array}{l}\text { FSH } \\
\text { IU/1 }\end{array}$ & $\begin{array}{l}\text { TSH } \\
\mathbf{m U} / \mathbf{1}\end{array}$ \\
\hline 0 & 0.9 & 2.8 & 3.4 \\
20 & 9.9 & 3.7 & 11.5 \\
40 & 8.3 & 4.2 & 9.4 \\
60 & 10 & 4.1 & 6.9 \\
80 & 9.2 & 3.3 & 4.6 \\
100 & 8.9 & 3,9 & 4.2 \\
120 & 6.8 & 8 & 3.6 \\
180 & - & - & 2.6 \\
\hline
\end{tabular}

\section{Case 2}

The patient was the product of a 28 weeks gestation, clomiphene induced to a 40years old mother, who was suffering from gestational diabetes managed with diet. She was para $1+0$. Spontaneous vaginal delivery with a birth weight of one kilogram. He was ventilated for 30 days and diagnosed with grade IV retina of Prematurity (ROP) which required laser therapy. There was no intraventricular hemorrhage. The patient suffered from recurrent attacks of hypoglycemia. At a blood sugar of $1.6 \mathrm{mmol} / \mathrm{L}$, serum concentration of cortisol was low at $65 \mathrm{nmol} / \mathrm{L}$ (normal; $150-630$ ), with also low ACTH level of $1.5 \mathrm{pmol} / \mathrm{L}$ (normal; 1.6-13.9). Serum concentration of growth hormone (GH) was 15,12 and $8.5 \mathrm{ng} / \mathrm{ml}$ (normal; >10) serum concentration of insulin was $6.3 \mathrm{mu} / \mathrm{ml}$ (normal; 5-21). Normal thyroid function tests; TSH of $4 \mathrm{mU} / \mathrm{L}$ (normal; $0.5-5$ ) and FT4 of $15 \mathrm{pmol} / \mathrm{L}$ (normal: 10-30) Normal hypothalamic pituitary gonadal function: $\mathrm{LH}$ of $3.9 \mathrm{u} / \mathrm{L}$ (normal; $0.5-3$ ) and FSH of 1.3U/L (normal; 1-5). Unremarkable MS/MS and VLCFA and urine organic acids. Magnetic Resonance lmaging (MRI) was unremarkable. He was started on hydrocortisone $2.5 \mathrm{mg}$ twice daily for two years that was then slowly tapered and stopped. Currently at the age of seven years his adrenal function was normal, serum concentration level was $175 \mathrm{nmol} / \mathrm{L}$ and serum ACTH of $5.5 \mathrm{pmol} / \mathrm{L}$, with a normal response to short Synacthen test (250ug i.v.) (Table 4). He remains well and growing normally and asymptomatic.

Table 4 ACTH stimulation test

\begin{tabular}{lll}
\hline & ACTH & $\begin{array}{l}\text { Cortisol } \\
(150-630 \mathrm{nmol} / \mathrm{L})\end{array}$ \\
$\begin{array}{l}\text { Adrenal Function } \\
\text { (Base-Line Result) }\end{array}$ & $\begin{array}{l}(1.6-13.9 \mathrm{pmol} / \mathrm{L}) \\
5.5 \mathrm{pmol} / \mathrm{L}\end{array}$ & $175 \mathrm{nmol} / \mathrm{L}$ \\
& $30 \mathrm{~min}$ & $60 \mathrm{~min}$ \\
Post Stimulation & 480 & 750 \\
Cortisol & & \\
\hline
\end{tabular}

\section{Discussion}

Isolated Adrenocorticotrophic Hormone (ACTH) deficiency is regarded as a rare disorder characterized by hypoadrenalism. It has been reported that this disorder is often accompanied by derangement of other endocrinopathy. Any process that involves the pituitary and interferes with corticotrophin (ACTH) secretion can cause secondary adrenal insufficiency. A diagnosis of isolated Adrenocorticotrophic Hormone (ACTH) deficiency is often difficult, and the disease has atypical manifestations and is occasionally accompanied by nonspecific findings. Most causes are secondary to autoimmune process such as lymphocytic hypophysitis, however, it may occur after traumatic head injury, ischemia, brain tumors, pituitary irradiation and surgery. Genetic causes are encountered in neonatal and childhood..$^{2-10,14-16}$ Insulin Tolerance Test (ITT) is considered the gold standard test to evaluate the hypothalamic pituitary adrenal (HPA), but has its disadvantages in clinical practice and that is the reason we prefer to the synacthen test, in most cases. ${ }^{17}$ The patients presented here ${ }^{18,19}$ were diagnosed as having isolated Adrenocorticotrophic Hormone (ACTH) deficiency according to the typical endocrinological findings as well as hormonal revaluation after a sufficient time interval on replacement therapy. The possible path physiologic mechanisms leading to this is poorly understood. A combination of factors are likely involved. Direct damage to the hypothalamic-pituitary adrenal (HPA) axis components, ischemic injury to the metabolically active adrenocortical cells. Also the patient's own immune and inflammatory response appeared to play an important role.

Prostaglandin (PGE) effects on the hypothalamic-pituitary adrenal (HPA) axis activation reduced by the inflammatory cytokines have long been suggested. ${ }^{13}$ A point to consider carefully in patients too, is the fact that recovery from the isolated Adrenocorticotrophic Hormone (ACTH) deficiency occurred, the reasons for this phenomenon is not yet clear. History regarding medications, brain trauma and infections should be obtained in every patient with isolated Adrenocorticotrophic Hormone (ACTH) deficiency. In conclusion, understanding the aetiologic pathophysiology of isolated Adrenocorticotrophic Hormone (ACTH) deficiency is quite essential for proper management. Continuous monitoring is crucial to differentiate between transient forms from permanent.

\section{Acknowledgements}

The author would like to thank Miss Hadeel NAl Jurayyan for her help in preparing this manuscript.

\section{Conflicts of interest}

The author declares there are no conflicts of interest. 


\section{References}

1. De Luis DA, Aller R, Romero E. Isolated ACTH Deficiency. Horm Res. 1998;49(5):247-249.

2. Oelkers W. Adrenal insufficiency. N Engl J Med. 1998;335(16):1206-1212.

3. Syriou V, Moisidis A, Tamouridis N, et al. Isolated Adrenocorticotrophin deficiency and Flexion contractures Syndrome. Hormones (Athens). 2008;7(4):320-324.

4. Nair GKV, Simmons DL. Adrenal Insufficiency Presenting as Hypocalcemia. Hospital Physician; 2002. p. 33-36.

5. Escobar Morreale H, Senrano Gotarreadona J, Varela C. Isolated Adrenocorticotropic hormone deficiency due to probable lymphocytic hypophysitis in a man. $J$ Endocrinol Invest. 1994;17(2):127-131.

6. Kasperlik Zaluska AA, Czarnocka B, Czech w. Secondary adrenal insufficiency associated with autoimmune disorders, A report of twentyfive cases. Clin Endocrinol. 1998;49(6):779-783.

7. Scoble JE, Harvard CW. Anosmia and Isolated ACTH deficiency following a road traffie accident: case report. J Neurosurg. 1990;73(3):453-454.

8. Sakai H, Yoshioka K, Yamagami K. Complete adrenocorticotropin deficiency after radiation therapy for brain tumor with a normal growth hormone reserve. Intern Med. 2002;41(6):453-457.

9. Vallette Kasic S, Brue T, Pulichino AM, et al. Congenital isolated adrenocorticotropin deficiency: an underestimated cause of neonatal death, explained by TPTT gene mutations. J Clin Endocrinol Metab. 2005;90(3):1323-1331.

10. Vallette Kasic S, Couture C, Balsalobre A, et al. TPIT gene mutation M86R associated with isolated adrenocorticotropin deficiency interferes with protein: protein interactions. J Clin Endocrinol Metab. 2007;92(10):39913999.
11. Hochberg Z, Hardoff D, Atias D. Isolated ACTH deficiency with transitory GH deficiency. J Endocrinol Invest. 1985;8(1):67-70.

12. Hiraiwa T, Furutama D, Sakane S. Isolated Adrenocorti cotropic hormone deficiency with transient thyroiditis inducing an adrenal crisis. Med Princ Pract. 2007;16(3):230-233.

13. Matsuoka Y, Furuyashiki T, Bito H. Impaired adrenocorti cotropic hormone response to bacterial endotoxin in mice deficient in prostaglandin E receptor EP1 and EP3 subtypes. Proc Natl Acad Sci U S A. 2003;100(7):4132-4137.

14. Kidess AI, Caplan RH, Reynertson RH, et al. Transient corticotropin deficiency in Critical illness. Mayo Clin Proc. 1993;68(5):435-441.

15. Thorner MO, Vance ML, Laws ER, et al. The anterior pituitary. In: Wilson J Foster DW, et al. editors. Williams Textbook of Endocrinology. 9th ed. Saunders, Philadelphia, USA; 1998. p. 279-280.

16. Debes MS. Adrenal insufficiency Overview. Endocrinology and metabolism syndrome; 2015.

17. Weintrob N, Sprecher E, Josefsberg Z. Standard and Low-dose short adrenocoticotropin test compared with insulin-induced hypoglycemia for assessment of the hypothalamic pituitary-adrenal axis in children with idiopathic multiple pituitary hormone deficiency. J Clin Endocrinol Metab. 1998;83(1):88-92.

18. Al Jurrayan NAM. Isolated Adrenocorticotropin deficiency as a rare cause of hypoglycaemia in children. Horm Res. 1995;44(5):238-240.

19. AL Jurayyan NAM, AL Issa SDA, AL Jurayyan RNA. Transient Adrenocorticotropic hormone deficiency in an infant. Case Report Clin Patho. 2017;4(1):56-58. 